\title{
"And Still We Rise...": Microaggressions and Intersectionality in the Study Abroad Experiences of Black Women
}

\author{
Tasha Y. Willis \\ California State University, Los Angeles
}

The Black female is assaulted in her tender years by all those common forces of nature at the same time she is caught in the tripartite crossfire of masculine prejudice, white illogical hate and Black lack of power. The fact that the adult American Negro female emerges a formidable character is often met with amazement, distaste and even belligerence. It is seldom accepted as an inevitable outcome of the struggle won by survivors and deserves respect if not enthusiastic admiration.

Maya Angelou, I Know Why the Caged Bird Sings, 1969, p. 291

Racial microaggressions are racial slights and subtle insults aimed at people of color. These may be verbal, nonverbal, and/or visual and may be automatic or unconscious (Solórzano, et al., 2000). These words and acts can accumulate over time to "contribute to diminished mortality, augmented morbidity and flattened confidence" (Pierce, 1995, p. 281). Such affronts, though often unintentional, have been documented to come at great psychic, emotional, and physical cost to the targeted individuals (Smith, Hung, \& Franklin, 2011). The term microaggression is also applied to women or other groups in society who experience oppression. These insults have been documented in the context of education for years (Solórzano, 1998; Solórzano, et al., 2000; Smith, Hung, \& Franklin, 2011). While it has been established that students of color often face racial microaggressions on their home campuses (Solórzano, 1998; Solórzano, et al., 2000), what happens when African American students study abroad? How is this experience complicated by the intersection of their gender, race, and socioeconomic class identities? This line of inquiry was the premise of the following study that used the Black feminist construct of intersectionality (Hill Collins, 1993; Crenshaw, 2005; hooks, 1994) to explore the experiences of African American women who studied abroad through community college programs.

Intersectionality originated as a central argument emerging from the Black feminist movement, as a critique of the feminist and civil rights movements. Foundational Black feminist theorists Crenshaw (1989; 2005), Hill Collins (1993; 2000), and hooks (1994) pointed out the double bind that women of color have long faced in a sexist and racist society and acknowledge the impact of socioeconomic class as well, which complicates matters further. hooks (1994) argues that sexism, racism, and classism are inextricably linked, and therefore, their intersection must be considered for more meaningful and accurate analysis of oppression. In other words, we are not a set of fragmented aspects of ourselves that are simply added together, but an amalgam at the convergence of our various social identities. We see the world through our own unique lens and the world interacts with us based on the particular dynamic created by the convergence of our gender, race, socio-economic class, and also our phenotype, ethnicity, sexual orientation, age, physical ability, spirituality, language, and myriad other aspects of our identities. Black feminist thought dismisses additive models of social oppression, instead focusing on the unique and potent interaction of one's social identities and related social forces 
(Collins, 2000). This idea is central to the guiding question of this study, which does not explore what it means to be black or female abroad, but instead what it means to be a Black woman abroad. I acknowledge that a fully intersectional gaze was beyond the scope of this project, which focuses on a mere two dimensions of participants' identities, rather than the myriad other aspects (e.g., socioeconomic class, disability, spirituality, etc.). Nonetheless, occasionally, other aspects surface and are thus included.

This article centers on the experiences of Black women who studied abroad through community colleges; this is an under-represented and under-studied group. Adding to findings of rich outcomes and positive experiences reported by students in my larger study (Willis, 2012), this study yields insight into participants' encounters with microaggressions related to their race and gender while abroad. Overall, participant outcomes were favorable and similar to those previously documented for White students at four-year colleges, however sojourners also faced racial and gender microaggressions from their host cultures and/or their U.S. travel peers in each of the three regions studied: the British Isles, the Mediterranean, and West Africa. Findings shed light on the complex interplay of race, ethnicity, gender, age, and other areas of social diversity for Black women abroad and underscore that campus climate extends beyond U.S. campus borders. Study abroad practitioners face an urgent call to action to address these issues both for Black women and for other students who face microaggressions based on different aspects of their identities, as well.

\section{Study Abroad: Benefits and Barriers}

A free bird leaps on the back of the wind and floats downstream till the current ends and dips his wing in the orange sun's rays and dares to claim the sky.

Maya Angelou, Caged Bird, 1986, p.183

Study abroad has been linked with numerous developmental benefits among college students and is also identified as a high-impact program that can lead to increased engagement and student success (Kuh, 2011). Commonly cited benefits relate to student development in four key, overlapping domains that contribute to international readiness: intellectual/academic (Ingraham \& Peterson, 2004; Hadis, 2005; Malmgren \& Galvin, 2008), intercultural (Paige, Fry, Stallman, Josic, \& Jon, 2009; Stallman, 2009; Williams, 2005), professional (Hunter, White, Godbey, 2006; Jayakumar, 2008; Lindsey, 2005), and personal (Locklin, 2010; Scoffham \& Barnes, 2009; Tesoriero, 2006). Examples of the kinds of outcomes common among U.S. study abroad students include discipline-specific learning, better understanding of an academic discipline within its international context, country- and region-specific learning, foreign language acquisition, and personal identity development (Ramirez-Clemens, 2002; Kasravi, 2009). Research to date has primarily centered on White, middle-class, female students at four-year institutions.

\section{Students of Color Abroad}

The body of research on study abroad among under-served students is skeletal, leaving many unanswered questions. Most of this work has documented the numerous barriers to study abroad for students of color (Brux \& Fry, 2009; Fels, 1993; Hembroff \& Rusz, 1993; Penn \& Tanner, 2009; Ramirez-Clemens, 2002). These barriers include financial constraints; lack of support from family, faculty, and/or friends; lack of programs in sites of interest; fear of the unknown; and not seeing a 
direct link to career aspirations (Acquaye \& Crewe, 2012; Comp, 2008; Fels, 1993). A limited number of studies exist regarding the study abroad experiences of students of color, primarily related to heritage seeking. In contrast to the general study-abroad literature, multiple sources identify heritage seeking or access to heritage-seeking destinations as important factors motivating many students of color to study abroad (e.g., Comp, 2008; Kasravi, 2009; Penn \& Tanner, 2009).

Among students of color in particular, studying abroad in heritage-seeking destinations contributes to their identity development by fostering a more grounded sense of who they are (Beausoleil, 2008; Ng, 2004; Raymondi, 2005), a deeper sense of purpose (Raymondi, 2005), and confidence in themselves (Day-Vines, Barker, \& Exum, 1998; Guerrero, 2006), all of which contribute to academic and career success. The literature reflects similarities as well as differences in the heritageseeking journeys of students of different backgrounds, which in turn reflect the complex intersectional nature of their realities abroad. Unlike most White students, who less frequently consider heritage seeking as a factor in their study abroad destination (Neff, 2011), it is common for African American, Asian American, and Latino/a American students living in the United States' White-dominated culture to expect an emotional homecoming experience if they choose a heritage destination (Brux \& Fry, 2009; Comp, 2008; Kasravi, 2009; Penn \& Tanner, 2009). These students also often experience dissonance at being perceived as "American" rather than being fully seen and embraced as people who have racial and/or ethnic ties to their host country (Comp, 2008; Wick, 2011). For example, African American students who attempt to "go back" to Africa or "the Motherland" often experience mixed feelings or disillusionment when they are lumped into the same "foreigner" category as their White peers (Landau \& Moore, 2001; Morgan, et al., 2002).

\section{Black Students Abroad}

However, there is little work examining the variety of factors that seem to influence how students of color will experience their time abroad; a gap in the research that this study begins to address. Additionally, few studies have focused on other outcomes aside from racial or ethnic identity development among those students of color who do participate in educational programs overseas, whether in heritage or non-heritage destinations. Existing research featuring or including Black students who study abroad offers insight into their experiences, though all are from four-year institutions and most focus on students studying in West Africa. Carey (2007) and Harden (2007) describe participants' racial and ethnic identities as ever shifting as opposed to fixed and attainable. While ethnic identity and, to a much lesser extent, intergroup relations are researched within this population, curiously absent are studies measuring the intercultural gains of African American students or students of color in general. The research of Day-Vines, et al. (1998) is a rare study of African-American students that employs Bennett's (1993) Intercultural Development Inventory (IDI), commonly used in the general study-abroad literature; this work describes five themes: "dispelling myths, liberating and inspirational experiences, contrasting values, psychosocial development, and achievement and motivation" (p. 3). Jackson's (2006) and Wick's (2011) participants articulated similar themes of "empowerment" and "agency" respectively, in addition to a strengthened sense of personal identity. This budding body of literature highlights the importance of research on a wider range of experiences among Black students abroad, and also reflects an absence of inquiry on microaggressions in this context. 


\section{Public Harassment of Women in Study Abroad}

Similar to research on students of color in study abroad, literature on gender issues in study abroad is also nascent. Only in the last 20 years have researchers begun to document women's genderrelated experiences (Rawlins, 2012). Given the wide cultural variances related to gender norms and tolerated behaviors, it is not surprising that women who study abroad have reported experiencing challenges when they encounter these differences (Fryer \& Wong, 1998; Rawlins, 2012; Talburt \& Stewart, 1999; Twombly, 1995). Rawlins' (2012) is the most recent inquiry and is representative of this body of literature. Through interviews with 18 U.S. women from a small East Coast liberal arts women's college, she sheds light on how participants responded to, accounted for and struggled to interpret public harassment abroad. Instances of catcalling, men being more forward than students were used to, men following them home and even exposing themselves publically to women was more disconcerting and frightening than the same types of experiences at home. Participants articulated finding appropriate responses in a different language presented a challenge yet also expressed a strong desire to not misinterpret "innocuous behaviors as harassment" due to cultural differences. Earlier, Fryer \& Wong (1998), Talburt \& Stewart (1999), and Twobmly (1995) explored the experiences of Japanese women in Canada, an African American woman in Spain, and white U.S. women in Costa Rica, respectively. Several of these studies began to touch upon the intersection of race, gender and nationality, yet leave ample opportunity for more in depth exploration of the subject.

\section{Community College Study Abroad}

Unfortunately, research regarding study abroad for students at community colleges is even sparser. Aside from one book chapter (Raby \& Valeau, 2007) and two national reports (Institute of International Education [IE], 2008; Raby, 1998), this review of the literature identified just three peerreviewed research studies. Two of these articles focused on students while the third examined institutions. Similar to the intercultural outcomes research discussed earlier, Emert and Pearson's (2007) study utilized the IDI, finding modest gains in worldviews and perspectives on cultural difference among participants who spent a semester abroad in either England or Costa Rica. The researchers did not note the ethnicity or race of their sample, which was drawn from a consortium of Minnesota state colleges and universities. Drexler and Campbell (2011) used a quantitative approach, measuring Chickering and Reisser's (1993) student identity development vectors and finding encouraging gains, and they call for replication using more racially and ethnically representative samples.

Focusing on the availability of opportunities for study abroad, Niser (2010) scanned the publically available data of 153 New England community colleges, identifying 113 (73\%) that offered study abroad programs. The use of third-party providers was the most common approach $(65 \%)$, followed by partnerships with international host institutions (41\%) and finally independent programs within specific community colleges $(19 \%)$. While these results show that the majority of community colleges in the New England region do offer the opportunity, what is less clear is whether the generic program offerings of third-party providers deliver desired institutional and programmatic student learning outcomes. Parallel to other career-oriented study-abroad research mentioned earlier (Acquaye \& Crewe, 2011), Niser (2010) also points out the importance of ensuring that programs leverage the "employability advantage" (p. 48) they can offer to students in the job market. These points echo a message expressed by Raby and Valeau (2007), who make a persuasive argument for the relevance of 
study abroad at community colleges. There is a clear gap in research on study abroad among community college students, which is even larger than that in research on students of color.

\section{Methods}

To explore the experiences and meaning making of African American female community college students who had studied abroad, I conducted a qualitative interview study. As previously noted, both community college students and African American students are underrepresented in study abroad and therefore identifying potential participants indeed proved difficult. Nonetheless, I recruited 19 women to complete semi-structured, retrospective interviews exploring their experiences and outcomes related to four domains of inquiry. I invited participants to reflect upon experiences within the context of their host countries and their phenotypes. The full results of the study were multifaceted and were in response to four guiding questions that probed for experiences related to intercultural communication, global identity, race and ethnic identity, other outcomes documented in the general study abroad literature, and potential microaggressions (Willis, 2012). For the current study, the most urgent results relate most directly to the last question: "How are racial and gender microaggressions experienced and managed by African American female community college students in heritage versus non-heritage destinations?" However, the occurrence of microaggressions was pervasive across all domains of inquiry. The focus of this article is to shed light on these experiences and to highlight ways in which we must better prepare our underrepresented students themselves for study abroad experiences, as well as preparing our campus communities to support these students. My decision to focus on this narrow band of findings for these purposes is consistent with Creswell's (2009) explanation of a researcher's choice of how to represent the data.

Intersectionality (Crenshaw, 2005; Solórzano, 1998; Solórzano, et al., 2000) serves as the lens through which I view and organize my interpretive inquiry (Creswell, 2009). Using inductive data analysis to develop themes and incorporating participant feedback through member checking, I aimed to create a holistic account (Creswell, 2009) of African American female community college study abroad alumni's experiences and outcomes. This analysis is holistic in that I have attempted to offer insight into the complexities of a variety of participants' situational experiences and to weave together a coherent larger picture. This is all done to shed light on the participants' meaning making within a qualitative design, the use of which, it is hoped, will be simultaneously enlightening, symbolic, and emancipatory (Rossman \& Rallis, 2003).

Through purposeful, snowball sampling, I recruited 19 women who met the following criteria: (a) had at least one biological parent who was of Black/African/African American/AfroLatino/Afro-Caribbean heritage, (b) had grown up primarily in the United States, and (c) had participated in some type of educational program abroad (outside the United States) at any point through a community college program. Snowball sampling led me to include participants from several cities. Thus, I conducted semi-structured, open-ended interviews in person in the Los Angeles area and the San Francisco Bay Area, and conducted five interviews via Skype with women in New York and Arizona. The interview protocol consisted of 21 questions and was refined after having been piloted with the first participant. The interview moved from low-risk to higher-risk questions. Examples of higher-risk questions related to microaggressions included: "What was it like being a woman of your racial background in (the country)?" and "What were your best and worst 
memories from the experience?" I also obtained participant data via a demographic survey, which I compiled into an Excel spreadsheet to glean a profile of the group.

I digitally recorded the interviews, had them professionally transcribed, and compared the transcripts with their recordings to ensure accuracy before utilizing the constant comparative method for analysis. This analysis entailed listening to recordings multiple times for a general sense of the data and its direction, tone and overall meaning (Creswell, 2009). My preliminary coding entailed breaking the text down into segments in order to begin making meaning of the larger interviews. Starting with the first interviews, I developed initial codes for similar kinds of ideas and phrases that recurred across participants, using in vivo codes where possible (Saldaña, 2009). As additional interviews were completed, I analyzed them as well to see if they fit into these initial categories. Using the constant comparative method (Lincoln \& Guba, 1985; Rossman \& Rallis, 2003), I began to develop my initial list of approximately 70 codes from the first five transcripts, which I hand-coded using colored markers. I conducted my last two interviews with Sophie and Robin, two of the younger participants, both of whom had been to Italy in 2011. In addition to interviewing them, I also shared my nascent themes with them to gain their perspective on my analysis. They both stated that my first impressions of the larger body of interviews resonated with them.

I then met with two peer debriefers (one African American woman and one woman of Filipina and White heritage, both of whom have spent time overseas) to share and discuss the initial code list and the themes as I was beginning to conceptualize them. They each hand-coded three transcripts that I selected from the group to represent students from diverse age groups and study abroad locations. They tested the stability of the codes, confirming that most of the codes were pertinent and durable across multiple interviews. I reviewed their coding to establish inter-coder reliability and then coded the remaining eight interviews. I then met with a third peer debriefer (another African American woman who has studied abroad multiple times) to explore with her the codes and themes I had been developing, creating a colorful visual map of these core themes and exploring how these may or may not be connected to my conceptual framework, which incorporates Chickering's (1969) identity development vectors and the concept of intersectionality. I stored all digital files with password protection on my laptop and all paper files of interviews, survey data, and consent forms in a locked file cabinet.

Based on this feedback, I uploaded all 19 of the transcripts into Atlas.ti (a qualitative analysis software program) and began the process of unitizing, categorizing, and coding for common themes across the entire body of data. In some cases, the data from individuals did not align with other data. This is noted as part of the process of negative case analysis (Lincoln \& Guba, 1985), to ensure that data that contradicts established patterns is not overlooked. I used Atlas.ti to create memos about these themes and the connections between them. I began to select exemplar quotes from the 19 participants for each theme and subtheme, to explicate through thick and rich description the insights and meanings participants shared with me (Creswell, 2009). I member checked in two ways: first, by sharing my analysis chapter with all participants, offering the chance to share any feedback verbally or in writing; and second, by conducting two gatherings, one in Los Angeles and one in New York City, at which available participants met each other and shared their experience of being part of the study and their reactions to my analysis. These opportunities were met with appreciation and participants' reactions validated my interpretations as reflective of their collective experiences. In one case, the 
small group in Los Angeles clarified an important point for me, shifting my concept of their awakened sense of "calling" or "vocation" to a sense of "self-actualization" instead.

It is important to note that there was ethnic diversity in the sample; several participants' parents were immigrants and several were of mixed heritage, as seen in Table 1. Though only five went to Africa (often considered a heritage destination for African American students), nearly half (nine) considered their destinations to be at least somewhat connected to their heritage. One was "unsure" and two "did not think about it" before their trips.

Table 1. Participant Overview

\begin{tabular}{|c|c|c|c|c|c|}
\hline Participant & Ethnicity (Self-Identified) & Country & $\begin{array}{l}\text { Perceived as } \\
\text { Heritage } \\
\text { Destination }\end{array}$ & $\begin{array}{l}\text { Weeks } \\
\text { Abroad }\end{array}$ & College \\
\hline Alana* & African American & $\begin{array}{l}\text { Morocco, } \\
\text { Ghana }\end{array}$ & Yes & 8 & MidCity CC \\
\hline Angel & African American & Spain & Yes & 8 & Beachside \\
\hline Antoinette & African American & Italy & No & 12 & Orange \\
\hline Arewa** & African American & Spain & No & 6 & Beachside \\
\hline Audrey & African American & Ireland & Yes & 3 & Valle Vista \\
\hline Betty & African American & Spain & No & 4 & Beachside \\
\hline Denice & $\begin{array}{l}\text { African American/ } \\
\text { Mexican/White }\end{array}$ & Italy & Unsure & 12 & Las Palmas \\
\hline Femi & African American & Ghana & Yes & 4 & MidCity CC \\
\hline Lanelle & African American & Spain & $\begin{array}{l}\text { Didn't think } \\
\text { about it }\end{array}$ & 4 & Beachside \\
\hline Minny & African American & Ghana & Yes & 6 & MidCity CC \\
\hline Nancy & Afro-Cuban/Salvadoran & Nigeria & Yes & 2 & Bay CC \\
\hline Nyla & African American & England & Yes & 4 & Metropolitan \\
\hline Robin & African American & Italy & No & 12 & Las Palmas \\
\hline Ruth & African American & Spain & $\begin{array}{l}\text { Didn't think } \\
\text { about it }\end{array}$ & 2 & Southwest \\
\hline Sabrina & African American & Italy & No & 3 & Valle Vista \\
\hline Sage** & African American & Spain & No & 4 & Beachside \\
\hline Sierra & $\begin{array}{l}\text { African American/ Puerto } \\
\text { Rican }\end{array}$ & England & No & 10 & Las Palmas \\
\hline Siray & African American/ Filipina & Nigeria & Yes & 2 & Bay CC \\
\hline Sophie & $\begin{array}{l}\text { Afro-Hispanic } \\
\text { (Dominican/Puerto Rican } \\
\text { [Indian, Spanish, African]) }\end{array}$ & Italy & Yes & 4 & MidCity CC \\
\hline
\end{tabular}

*Alana did two 1-month programs in 1 year at MidCity and two 1-month programs (in India and Spain) after she transferred to a 4-year institution. Only the MidCity trips are reflected here, though her interview responses likely include reflections from all four trips.

**Arewa and Sage participated through a community college program after they had already graduated from 4-year institutions.

\section{Trustworthiness}

Naturalistic researchers establish trustworthiness through common practices which now set the standard for rigorous, credible qualitative research (Creswell, 2009; Rossman \& Rallis, 2003). This qualitative study incorporated many of Lincoln and Guba's (1985) approaches to enhance its design, findings, and implications in terms of credibility, consistency, neutrality, and applicability. Specifically, to address the issue of "truth value" (or credibility), I ensured that my sample was large enough to 
reach saturation, strove to build rapport from the first contact with each participant, incorporated member checking, and deliberately brought to my peer debriefers' attention any data that did not fit into the patterned codes as a means of conducting negative case analysis (Lincoln \& Guba, 1985). To achieve consistency, I included thick, rich description in the form of exemplar quotes, an audit trail, and a researcher's journal in which I documented the decisions I made related to the research process, as well as notes from conversations with my committee members, peer debriefers, and member check sessions. To establish neutrality, in addition to the researcher's journal, I included reflexive journal entries and consultation with a researcher who has expertise in ethnographic interviewing, identity development, and intercultural education, who provided feedback on my pilot interview recording that helped me refine my interviewing skills. Lastly, it is my hope that through the provision of thick, rich description in the form of numerous exemplars from the interview transcripts in addition to demographic data, I have provided the "data base that makes transferability judgments possible on the part of the potential appliers" (Lincoln \& Guba, 1985, p. 316).

\section{Findings}

Through this qualitative interview study, I explored the experiences of 19 Black female community college students who studied abroad in the Mediterranean, West Africa, and the British Isles. Though participants described their trips as positive overall, they also faced disheartening and even painful encounters as a result of being Black women, both in their host cultures and among their non-Black U.S. peers. Racial and gender microaggressions certainly occurred in regions not commonly conceived of as heritage destinations for African American students, such as the Mediterranean and the British Isles. However, they also occurred in places where students had anticipated feeling cultural connection and thus were more surprised to encounter them, places such as in Ghana, Nigeria, and Morocco, and in ethnic enclaves of African immigrants in the Mediterranean.

\section{Microaggressions by U.S. Peers}

You may not control all the events that happen to you, but you can decide not to be reduced by them.

Maya Angelou, Letter to My Daughter, 2009, p. xii

Study-abroad programs take students into challenging contexts in new cultures. In some cases, students travel alone and are immersed completely in the culture, living with local host families by themselves and/or enrolling in institutions with local students, largely left to adjust on their own. However, in many cases, students travel with a group of U.S. peers in classes and/or in their living arrangements with host families. This peer connection can serve as a cultural buffer and a source of comfort during the process of adjustment to the new environment. In this study, all participants were engaged in the latter, more insulated type of study-abroad trip. As a result, U.S. peers played a significant role in shaping participants' experiences. Further, most participants in this study had at least one other Black student on their trip, which ultimately proved to be a very helpful resource.

Though the majority of participants experienced the comfort of having other Black students on their trips, four students did not. Antoinette (Italy), Nyla (England), Ruth (Spain), and Sierra (England) were the only Black women on their trips. Both Antoinette and Nyla reported having had previous experience being immersed in White and multi-ethnic settings, yet both still experienced some 
discomfort on their trips. The fact of being the only Black woman was a bit disconcerting for Antoinette during her semester abroad:

So, it was like I really didn't have that, that other, that other bond with someone that could understand the same experience; because my experience was completely different from everyone else's. Because there were other Hispanics, there were other Asians, there were other Whites. There were no other Blacks, so it was just me. So, so ... I am, I'm used to it, I am used to it but then again, it's still different and then it's also, it's a little lonely .... . Because you don't have, you know, that base where you have someone who can, who can understand .... It was like I am a black dot on a White piece of paper. And it is like... I didn't fear for my life, or anything. I wasn't afraid or anything like that, it was just like I don't have anyone that can share ... people who, you know, can understand your plight and what you're doing and what you're going through.

Such isolation was often compounded by experiences of racial microaggressions perpetrated by U.S. peers and/or participants' host cultures. For example, though being the only Black student on the trip was uncomfortable in and of itself, Nyla also cited specific actions by her U.S. peers that heightened her feelings of isolation and marginalization:

Just some of the comments that they would make were a little bit uncomfortable...

But I just laughed it off as a joke. I mean I just let it slide. But at the same time, I started to distance myself from them. I noticed that I wouldn't hang out too much with them going out or I wouldn't hang out with them in a lot of large crowds.

When asked to compare her interactions with British people to those with her U.S. travel peers, Nyla summarized by saying, "Most interactions or huge emotions came from just interacting with the students that came on the trip with different things they would say and everything."

Even students who did have at least one other Black woman on their trip could also experience racial isolation. However, for most of the participants who went to Spain, the difficulty of feeling racially othered was largely mitigated by the presence of multiple other Black travel companions. In fact, Angel, a Los Angeles participant who went on one trip and later recruited a cadre of Black women to travel with on her next trip, had a significant impact on her peers. Two of three interviewees on the same trip specifically cited Angel as a source of crucial pre-departure information and incountry support. She helped prepare Betty emotionally before the trip as a Black woman, and she was a source of comfort for Sage when she encountered racial taunting by a Spanish school-aged child. Interestingly, Angel (49) and Ruth (62) were the two oldest students in the group, and both described themselves as being in mentoring roles in relation to their peers. Their life experiences likely served as helpful resources for them in managing their most challenging experiences. These examples raise another important aspect of a student's experience abroad, particularly in the context of the highly age-diverse community college programs; their age and maturity, which warrant further examination in a separate study.

Largely, the other women interviewed reported positive experiences with peers, citing the deep bonds and new friendships they developed as some of the most rewarding aspects of their trips. In several cases, however, White peers were sources of discomfort and isolation. In some cases, 
microaggressions from peers were actually more troubling than any the student may have experienced from the local culture. Robin provided this example:

One of the girls in the group, her name was Lynn ... [and] there was another girl named Julia. So, Lynn told Denice, 'You know, Julia acts more black than you do. You don't even act black,' and Denice was like, 'Okay, well, how am I supposed to act?' I remember Denice coming home. I wasn't with her. So, she came home and she told me the incident, and she was like, 'Stuff like that is just annoying, you know,' and we had this conversation about it. And we did have those talks a few times while we were there... .

Both Denice and Robin recount this and several other instances in which they encountered racial stereotyping from their U.S. peers. They found it very helpful to be able to process these moments with each other, as the only two Black women on the trip.

Sabrina recounts that in addition to her male cousin who was with her in Italy, there were two other Black students, one male and one female. She and the other Black woman were relieved to relate to each other and Sabrina "needed those moments." She explained that within their group, there seemed to be a divide between the White students and other students. Her Black female friend in particular experienced isolation in her living arrangements, which were exacerbated in the larger group:

It was the fact that she was in an all White girl apartment. And so they really didn't share different information with her. So if they would go to a party they wouldn't tell her. They wouldn't really ask her. So she would just kind of be left alone. And she was older. She was like 27 or 28 and they were like 22, 23. They really didn't share that much information with her.... And that's the other situation that happened. The White people would stay to themselves .... And the rest of the people that were not White, we would be in a group ... - And so we would kind of discuss amongst ourselves as ethnicities, as the minority in a way ... that 'How come they just don't hang out with us?' And we would invite them and they don't come. And they would go places and they wouldn't invite us. So we were just like 'What?' We didn't understand we're like, 'We're from the same school, like, what's going on?’

Again, in this exemplar, the relevance of age, as well as race, should be noted as possibly playing a role in the lack of connection among students sharing the same apartment. This factor leads back to another intersectional consideration: participants were not only of Black heritage but were also of a particular age and gender, which likely had a bearing on their experiences. Such age differences on a trip may be fairly unique to the community college experience, but because of their potential impact they are nonetheless important to note for study abroad practitioners at all institutions.

Microaggressions by In-Country Hosts

...You may shoot me with your words,

You may cut me with your eyes,

You may kill me with your hatefulness,

But still, like air, I'll rise...

Maya Angelou, And Still I Rise, 1978, p.41-42

Strikingly, all 19 students experienced some form of microaggression, either from U.S. peers or from the host culture. In this study, microaggressions occurred in all three host regions but were most 
pronounced in Spain and Italy, in reaction to the participants' intersectional identity as Black females abroad. These experiences offer evidence of gendered racism (Smith, Hung, \& Franklin, 2011) toward participants while overseas.

In West Africa, women experienced microaggressions related to their sexual orientation and skin color in combination with their gender. Participants Siray and Nancy, who studied in Nigeria, pointed out that the assumption that they were heterosexual despite their initial attempts to explain that they were not interested in men was striking. Hearing homophobic comments, they quickly learned that it was not safe to be "out" in the way they were proud to be as lesbian and bi-sexual women at home in the San Francisco Bay Area. Participant Minny, who studied in Ghana, described messages she received not from individuals but from the larger culture about standards of beauty for Black women. Minny shared, "We went into one particular village and they would sell this bleaching cream. These ladies' faces were so third-degreed burned because of the cream that they was using just to get lighter. They had this false idolization of light skin is beautiful and you're not supposed to be this way and you're supposed to have all...I mean, it was just sad." Femi, also in Ghana, noticed that Ghanaian men tended to gravitate to the lighter-skinned, biracial and white women on the trip. They did not mention how skin color and the standard of beauty (handsomeness) may have applied to Black men.

Examples of host culture microaggressions in Europe were plentiful and are distinguished from more overt incidents of actual harassment, which participants reported less frequently. Angel's boyfriend, who is White, visited her for a few weeks during her trip to Spain. In Madrid, they encountered non-verbal hostility as people seemed unprepared or uncomfortable “. . . to see a Black woman with a White man. I got horrible looks and stares and just the body language, nonverbal mind you. They never said anything derogatory to me. It was all nonverbal body posture, [body] language, the rolling of the eyes, the turn up of the face, the turn away of the head." Others may overlook or minimize these experiences, yet they weigh on recipients, like Alana and Sabrina, who are left to wonder about these instances. As Smith, Hung, and Franklin (2011) point out, these experiences "consume valuable time and energy that could be used for more creative, educative, professional or humanitarian goals" (p. 67).

When asked about any difficult experiences, Lanelle and Betty, both in their late 30s and friends on the Spain trip, both described going out for dinner one evening. They recounted that there was some misunderstanding that led Betty to get up from the table and approach the bar for service.

Lanelle: [Betty] didn't appreciate standing there and [the bartender] saw her the whole time, didn't address her, didn't say anything to her. We wanted to leave and one of the patrons in the restaurant got into the conversation ... he got up and he got loud and he got in [Betty's] face, chest to chest, and bumped her and started telling her, 'You're going to pay for that,' and just started going off. He was a native of Spain, but he just started completely going off and he had nothing to do with nothing. So that was very ugly. That was very, very ugly.

Both participants attributed this experience to race. It is important to note that part of the challenge of microaggressions is that they can be very subtle, making them easy to discount by people who may not be experiencing them directly, yet they weigh on the receiver (Pierce, 1974; Sue, et al., 2007). For example, Alana drew a comparison between the non-European places she studied (Morocco, Ghana, and India) and Spain: 
You know, it was like a subtle racism. So it was more so ... you know, I remember hearing from my roommate that our housemother basically was racist in that she had said really mean things. She didn't reveal to me what the woman said, but whatever the case, you know ... I didn't ask. You'd go into the stores and people just have a certain attitude ... when I went into the store sometimes, people had different attitudes. But then some people would say, 'Well, they don't like you because you don't speak Spanish,' and we'd be like, 'Oh, okay, maybe that's what it is. Thanks, that explains everything,' but, you know, sometimes that wasn't it, you know?

The subtlety of microaggressions is further exemplified by Angel's description of trying to go to dinner with her White American boyfriend who was visiting her in Madrid: “. . . dinner time in Spain is usually about 9:00 or 10:00. If you get there earlier for dinner, chances are you won't be served. We weren't served at 11:00. They were like, 'No. The kitchen's closed. No la comida. No abierto. [No food. Not open.]' And I'm like, 'Do we have the same time? Did the time change here?"' Angel's experience reflects the intersectional nature of this microaggression; her sense was that it was in response not only to the fact that she is Black, but to the fact that she was a Black woman in an interracial relationship with a White man.

Just as microaggressions can be overtly racial or more subtly perplexing and hurtful, so too can incidents that target people for multiple aspects of their identity, such as being female and Black, or female and of a particular size and/or sexual orientation. A variety of students in the Mediterranean and British Isles expressed awareness that they received particular attention, some appreciated and some not, as a result of their intersectional identities. In both Spain and Italy, participants commented that the cultural norms regarding gender were clearly different from what they were used to in the United States. Betty encapsulates the experience of many when she refers to how some men would call out to her and other Black women:

They definitely commented on my skin color. Chocolate, you know, stuff like that. I think there was another word they used too ... Morena ... Not conversing. Not like to talk like that. But more catcall type of thing.... Sometimes it was okay and sometimes you could tell it was a little rude. You know. I'm not big on catcalls, regardless.

This hyper-sexualized experience for Black women is also seen in the literature for another Black woman in Spain who encountered more vulgar and sexualized catcalls than her White U.S. female peers (Talburt \& Stewart, 1999).

Sophie, a 21-year-old Dominican and Puerto Rican American who spent a month in Italy, explained that on her trip, there were two other Dominican American women. She explained how they all received attention from Italian men as a result of their skin color, hair texture and gender. On one hand, this might seem flattering; yet Sophie points out the discomfort of feeling othered among her U.S. peers.

And especially the ones who had the kind of features that we did with like the big hair and skin color; when we tanned we got darker than we normally are and with a richer color, so they took a liking to us for a different reason [from our non-black peers] in a weird way because we were exotic to them because they don't normally experience our type of background and our kind of women, but at the same time there was moments where we felt other[ed]. 
In addition to catcalls and being hit on as a result of being a Black woman in Italy, Sabrina, a vivacious and artistic 20 -year-old, recounts being stopped by a policeman as she and a girlfriend walked home late at night:

So he kind of stared and he kind of said something in Italian and I was just like 'What? Non capisco.' And he kind of drove away like 'okay you're fine because you don't know what I'm talking about.' And so I guess that was one of the major things that actually happened. That I kind of got not pulled over, but a police officer really kind of paid attention to me. So I'm just like, 'Okay, I'm not a prostitute. I'm just an [Black] American.'

Sabrina went on to describe the stereotypes and sexualization of Black women she experienced in Italy, which, thankfully, she had read about through "doing her [own] homework" before she went.

Intersectionality is also useful in helping to untangle another challenging situation encountered by two participants staying with the same family, which highlights language, skin color, age, and body shape. Initially, Lanelle identified the language barrier as a concern within the context of her home stay experience, especially given that the other students housed in the same host family spoke more Spanish than she did.

... so it was, um, a barrier between me and the, the [home]stay mother in terms of me trying to communicate with her and, um, it was a little intimidating because some of the young ladies that were there, they had studied Spanish for a very long time.

This circumstance was challenging for Lanelle, a student in her late 30s who is friendly and has a calm, mature personality. Interestingly, one of her housemates in the program, Sage, an outgoing, confident young woman in her 20s, volunteered her perspective on the situation during her own interview. From Sage's point of view, the fact that Lanelle did not speak much Spanish was compounded by the fact that their home-stay mother seemed quick to draw comparisons between the two roommates, blaming Lanelle's lack of Spanish skills, and their relationship disconnect, on the fact that Lanelle is of a darker complexion than Sage. Sage, who had traveled internationally before, spoke freely about race and racism during her interview:

She [Lanelle] was like, darker than me and she didn't speak as much Spanish as me. So, my house parents didn't speak any English .... So over the course of our time there, they would make big differences. We're both morena. And then she [the host mother] would be like, 'yeah, but she's darker.' I'm like, 'it doesn't matter. We're the same.' Just because they didn't like her as much, they wanted to kind of attribute 'she's darker and she's . . .' It doesn't matter. We're black. That's just what it is. Don't kind of attribute the fact that you don't like her with her skin color or anything like that.

In contrast to Sage, Lanelle did not initially attribute the rift between her and her home-stay mother to race or skin tone in her interview, though during member checking, she did clarify that not only was race likely at play, but also possibly her relative age and body shape. Though she could not be certain, she wondered if perhaps the home-stay mother was used to younger students and/or may have been intimidated by Lanelle's maturity and shapeliness as a Black woman. During member checking, Lanelle was flooded with memories of being scolded at the dinner table to the point of crying, and also being denied a key to the host family's apartment, unlike the other students in the home, all of whom received keys immediately upon arrival. Unfortunately, she did not feel 
comfortable addressing this with the program faculty until very late in the trip. This was largely because when she first shared that she was not given a house key, her program faculty unwittingly minimized or dismissed the situation as a simple mistake about which there was no need for concern. This minor oversight contributed to Lanelle's hesitation to raise the much more serious issue of sexual harassment described below, which was of great concern to the program staff once they heard about it.

\section{Racialized Sexual Harassment and Assault \\ Leaving behind nights of terror and fear, I rise \\ Into a daybreak that's wondrously clear, I rise \\ Bringing the gifts that my ancestors gave, I am the dream and the hope of the slave. I rise, \\ I rise, \\ I rise.}

Maya Angelou, And Still I Rise, 1978, p.42

Beyond the realm of microaggressions, several students were confronted with unwanted sexual behavior and even physical contact that, by U.S. standards, would be classified as sexual harassment or assault. Though it is not entirely clear, an intersectional gaze acknowledges that these presumably gendered experiences were likely complicated by the participants' perceived race, as well as their sex and other aspects of their intersectional identities.

As noted earlier, during member checking, Lanelle was inundated with memories of difficulties she encountered with her home-stay mother. During the same member checking phone call, she also suddenly recalled another painful memory related to her host father, which she had buried deeply. With reticence, she shared that when she was home alone on the weekends (as she did not leave for excursions with her peers and the host mother would go out for the day), her host father would retreat into a room sharing a wall with her bedroom and play pornography with the volume turned up very loud, which made her very uncomfortable. She reflected upon her approach to coping with this daunting set of experiences: she realized that as a way to keep functioning during the trip, she had minimized the racial undertones of her experiences and the pain that came with them. Though Lanelle avoided drawing definitive conclusions about these incidents, she did wonder if her body shape, gender, and age, in addition to race, fed into her host father's behaviors in her presence. This example highlights the relevance of intersectionality in understanding the possible experiences of Black women studying abroad. Their diversity in physical phenotype, age, language skills, and personality, as well as their approach to managing race, discrimination, and even harassment, contribute to their differing experiences in a host country among both hosts and U.S. peers. It also emphasizes the emotional energy spent by recipients of such ambiguous experiences, and the psychic toll such experiences take on them.

Less ambiguous and further on the spectrum of affronts is actual sexual assault, defined as any unwanted physical contact of a sexual nature. Sophie had a frightening situation occur that definitely involved her gender and may or may not have involved her race. She shared about an instance in which she was separated from her friends and ended up walking home alone from the evening's activities. A man on a bike began to follow her, "and he was like hissing and saying these things in 
Italian that I could understand like 'American girl' and all of these things and I was getting really, really freaked out and panicking ..." She began looking for safety or someone safer to approach, with no luck. To her relief, she finally spotted a man with a dog who seemed approachable and he exchanged terse words with her follower, who finally left. As she was getting re-oriented to head home, the man who had just helped her,

goes to say goodbye, and in the Italian culture, they can be very affectionate to a different degree than what you're used to as an American, so he goes to do the whole hug and double cheek kiss and then he pulled me in for like a real kiss, and I like freaked out and just ran to my hotel room.

Sophie was not alone in this experience. Denice, in Italy for a semester, described that as a whole, both women of color and others in her group encountered similar experiences.

We all got grabbed before .... Their women aren't really seen as people kind of sometimes, and that's kind of how it felt. Like they would whistle at us, and [say] like, 'Oh, just come here.' And like we saw one of my friends, because she was like, 'No.' And like he grabbed her by the hair, and it was just a big incident.

These gendered incidents were troubling for the participants in Italy in particular, and they spoke of the need to adjust to this cultural difference regarding what is publically condoned in that country. What is not clear is the extent to which these situations also involved race, or other aspects of participants' social identities given the cultural context.

\section{Discussion}

Exploring participants' peer interactions and their experiences with members of the host culture shed light on important yet under-examined aspects of Black women's study-abroad experiences. In similar ways, the racial demographics of the countries in which students studied and the demographics and dynamics of their peer group clearly influenced students' feelings and reactions. In some cases, students built deep friendships with peers; in others, they experienced racial microaggressions and isolation from peers and/or the host culture. By no means were these mutually exclusive occurrences. In some instances, participants even experienced sexual harassment or assault, according to U.S. definitions, which may have been complicated by their race, age, or other aspects of self. Overall, some patterns emerge: (a) in West Africa, students reported environmental messages they received related to gender, sexual orientation, and skin color, but they did not explicitly report being the target of direct racial microaggressions from U.S. peers; (b) in the British Isles, although participants did not experience microaggressions to a great degree from their host communities, instead, two participants describe disturbing racial isolation and microaggressions from their U.S. peers; and (c) in the Mediterranean, most participants cited having the support of other Black women as companions in facing the challenging microaggressions they encountered from both peers and the host culture as very important to their ability to cope with these stressors away from home. Though microaggressions may not be intentional, they weigh on the targets of these incidents and as a result, the recipients often experience racial battle fatigue in the form of psychological, physiological, emotional, and behavioral stress responses (Smith, Hung \& Franklin, 2011). Even further, in several disturbing instances, sexual harassment and assault were reported in the Mediterranean. Students experiencing sexual harassment have been documented before (Fryer \& Wong, 1998). Ultimately, the way students made meaning of 
these racialized and gendered experiences may also relate to the way they perceived and managed these aspects of their identity and related social oppressions at home.

Fortunately, though participants had some negative experiences related to race and gender, students were resilient and rose above these experiences, such that the challenges were largely outweighed by their immensely positive experiences overall. In fact, analysis of the full data set documents participants' descriptions of many of the same kinds of developmental experiences reported in the general study abroad population's sojourns: deciding to explore a new culture, preparing to do so by gathering the necessary resources, engaging in pre-departure orientation, entering the host culture, confronting the myriad challenges that this experience outside one's comfort zone presents, and finally, returning home with new insights about one's self and one's own culture, in addition to one's hosts. The women in this study also grew in the same rich areas that their White peers often do in terms of personal, intercultural, and academic growth (Willis, 2012). In fact, the participants used words such as "incredible," "fantastic," and "phenomenal" to encapsulate their experiences and to describe how they transformed in remarkable ways. Participants also universally wished all students of color could take part in study abroad.

\section{Practice Implications and Recommendations}

To be clear, in highlighting the positive outcomes for the participants, by no means do I seek to minimize the realities and obstacles they overcame. My intention is to amplify their collective voice by emphasizing the immense power of study abroad, while also drawing attention to the urgency of improving not only access to but the quality of the experience for marginalized students.

A variety of practice implications may be of interest to study abroad faculty, staff, and directors at community colleges, four-year institutions, and even third-party providers. In particular, the demographics of community colleges can result in more diverse travel groups, which can be helpful for students of color, yet call for more attention to issues of campus climate and staff/faculty preparedness related to study-abroad programming.

\section{Travel Peers}

At community colleges, there is often greater racial diversity on campus than in predominantly White institutions or even at relatively more diverse four-year public institutions. This holds several important benefits for community college study-abroad programs. First, these programs are often more racially diverse than programs at four-year schools, which means community college programs can potentially offer greater levels of support and comfort from culturally similar peers for Black students and other students of color, depending upon the campus demographics. Such diverse study abroad programs also yield opportunities for participants' further intercultural development among their U.S. peers, which can be of great benefit upon return home to their multicultural campuses. Students may develop a deeper connection to and interest in the culturally different others they will encounter on their home campuses, which has implications for student connection and engagement and thereby for academic retention (Kuh, 2011). This is a crucial issue for community colleges, where attrition is high (Shulock, Moore, Offenstein, \& Kirlin, 2008). However, campus climate must be addressed both at home and abroad, to support greater diversity in study abroad groups. 


\section{Campus Climate}

Issues of campus climate are widely discussed in the literature and amongst student and student affairs professionals (Hurtado, et al., 1999; Locks, et al., 2008; Milem, Chang, \& Antonio, 2005). Yet, as demonstrated in this study, campuses expand beyond their own physical borders when they offer programs overseas. Thus, consideration should be given to the racial composition of a travel group, in order to facilitate group cohesion. Orientations should include awareness-raising activities that directly broach the topics of race, gender, and other salient aspects of identity. While in the host country, faculty and/or staff should facilitate regular check-in points and proactively initiate dialogue with the group. During these routinely scheduled points, faculty can assist students in processing their learning overall, but they should also directly inquire about how students are experiencing their identities in the host culture and among their peers. This would serve both to address potential concerns and to create a climate in which subjects like race, class, gender, age, disability, and sexual orientation are safe for students to raise before, during, and after these check-ins, and even upon return home. During re-entry activities, faculty should continue to invite reflection about how diversity impacted the individual and collective experiences of the travelers. This can serve to deepen the learning for all students as well as to validate any concerns students of color or other specific groups may have had. The capacity of faculty and staff to take this approach cannot be taken for granted, and can in fact require significant advance preparation, including substantial self-awareness.

\section{Critically Self-Reflexive Faculty and Staff}

Taking a proactive stance to meet the needs of students requires that study abroad faculty and staff be reflexive practitioners, capable of considering their own comfort and preparedness in addressing diversity issues. Are they prepared to facilitate these kinds of sessions? Do they have the skills needed to truly create safe spaces in which diverse students can have their needs met? Do faculty and staff recognize microaggressions when they occur, or do they dismiss them as students being "overly sensitive" or "imagining things?" How will faculty and staff address microaggressions if they notice them, or if they are brought to their attention? What messages do they send to students about how much they can trust their faculty or staff to support them through challenging incidents? Faculty must be prepared not only to avoid tacitly condoning microaggressions and racism, but to be proactive in creating a safe climate for all students to both enjoy and maximize their learning abroad. This is an example of an area where internationalism, U.S. domestic diversity, and campus climate issues converge. Unfortunately, the intercultural communication skills and eager curiosity about other cultures that are common among international education practitioners may fall short if they are not also equally equipped with the specific awareness, knowledge, and skills necessary to effectively navigate the loaded racial and other socio-cultural dynamics of the United States domestically.

\section{Conclusion}

Study abroad for Black women in community college is a powerful yet largely untapped resource, offering opportunities for growth in terms of students' agency and empowerment, intercultural development, and in some cases, their sense of calling and self-actualization (Willis, 2012). Many of the women in this study had emancipatory experiences that raised their consciousness of themselves as potent agents in the world (Willis, 2012).

However, these promising outcomes, as powerful as they are, were only part of the whole story for participants. In fact, an intersectional analysis revealed that race, gender, class, age, sexual 
orientation, and other aspects of participants' social diversity shaped what they experienced in their interactions with their peers and their in-country hosts. How participants managed social oppression is salient to their collective counter narrative. These experiences have not previously been deeply explored in the study abroad literature. Therefore, this study extends previous research by offering compelling insight into the realities of study abroad for a very under-served and important set of students. Continued inquiry of this nature will give further voice to other Black women and men, community college students, students of different racial backgrounds, and other under-served students in study abroad programs. Such narratives will counter dominant perceptions and knowledge based primarily on the experiences of middle-class, White females from four-year institutions who study for a semester or longer, often in Europe.

An important cautionary reminder from this exploration is that racial dynamics, racism, sexism, and microaggressions do not mystically enter temporary stasis during study abroad sojourns, and therefore cannot be ignored. Though the participants in this study managed these challenges well, they were not all prepared by their institutions to do so. Instead, participants drew upon their own life experiences and each other as important resources. Though this had some unexpected benefits, such as many students returning home with a tighter peer network, the reality is that campus climate extends beyond the geographical boundaries of an institution's local community. As leaders in higher education and specifically in study abroad, we have a responsibility to ensure that campus climate issues are anticipated, taken seriously, and addressed proactively in study abroad programs, much the way progressive leaders strive to do so on their home campuses within the United States. We must explore ways to enhance our faculty and program capacities to meet students' needs. In short, as Dr. Angelou wrote, she would have us ensure that our students depart for their sojourns "hoping for the best, prepared for the worst, and unsurprised by anything in between” (1969, p.308).

\section{References}

Acquaye, L. A., \& Edmonds Crewe, S. (2012). International programs: Advancing human rights and social justice for African American students. Journal of Social Work Education, 48, 763-784. doi:10.5175/JSWE.2012.201100130

American Association of Community Colleges. (2012). Fast facts. Retrieved on April 20, 2012, from http://www.aacc.nche.edu/aboutcc/pages/fastfacts.aspx

Angelou, M. (1969). I Know Why the Caged Bird Sings. New York City, NY: Random House.

Angelou, M. (1978). And Still I Rise. New York City, NY: Random House.

Angelous, M. (1986). Poems. New York City, NY: Bantam.

Angelou, M. (2009). Letter to My Daughter. New York City, NY: Random House.

Banks, J. A. (2008). Diversity, group identity, and citizenship education in a global age. Educational Researcher, 37(3), 129-139.

Beausoleil, A. (2008). Understanding heritage and ethnic identity development through study abroad: The case of South Korea (Doctoral dissertation; University of California, Santa Barbara). Retrieved from Dissertation Abstracts International. (AAT 3330411)

Bennett, M. (1993). Towards ethnorelativism: A developmental model of intercultural sensitivity. In R .M. Paige (Ed.), Education for the intercultural experience (pp. 21-71). Yarmouth, ME: Intercultural Press.

Bennett, M. J. (2009). Defining, measuring, and facilitating intercultural learning: A conceptual introduction to the intercultural education double supplement. Intercultural Education, 20, 1-13. doi:10.1080/14675980903370763 
Brux, J. M., \& Fry, B. (2009). Multicultural students in study abroad: their interests, their issues, and their constraints. Journal of Studies in International Education, 20(10), 1-19.

Carey, K. (2007). The shifting character of social and ethnic identity among African-American sojourners (Doctoral dissertation; Howard University). Retrieved from Dissertation Abstracts International. (AAT 3283227)

Chickering, A. W. (1969). Education and identity. San Francisco, CA: Jossey-Bass.

Chickering, A. W., \& Reisser, L. (1993). Education and Identity. San Francisco, CA: Jossey-Bass.

Collins, P. H. (1993). The sexual politics of black womanhood. In E. G. Moran (Ed.), Violence against women: The bloody footprints (pp. 85-104). Thousand Oaks, CA: Sage.

Collins, P. H. (2000). Black feminist thought: Knowledge, consciousness, and the politics of empowerment. New York, NY: Routledge.

Comp, D. (2008). U.S. heritage-seeking students discover minority communities in Western Europe. Journal of Studies in International Education, 12(1), 29-37.

Crenshaw, K. (1989) Demarginalizing the intersection of race and sex: A Black feminist critique of anti-discrimination doctrine, feminist theory, and anti-racist politics. University of Chicago Legal Forum, pp. 139-167.

Crenshaw, K. (2005). Mapping the margins: Intersectionality, identity politics, and violence against women of color. In R. K. Bergen, J. L. Edleson, \& C. M. Renzetti (Eds.), Violence against women: Classic papers (pp. 282-313). Auckland, New Zealand: Pearson Education.

Creswell, J. W. (2009). Research design: Qualitative, quantitative and mixed methods approaches. Los Angeles, CA: Sage.

Day-Vines, N., Barker, J. M., \& Exum, H. A. (1998). Impact of diasporic travel on ethnic identity development of African American college students. College Student Journal, 32(3), 463-471.

Drexler, D. S., \& Campbell, D. F. (2011). Student development among community college participants in study abroad programs. Community College Journal of Research and Practice, 35, 608-619.

Emert, H. A., \& Pearson, D. L. (2007). Expanding the vision of international education: Collaboration, assessment, and intercultural development. New Directions for Community Colleges, 2007(138), 67-75.

Fels, M. D. (1993). Assumptions of African-American students about international education exchange. Internationalizing the Speech Communication Curriculum: International Students and Multiculturalism in American Higher Education, pp. 1-22. ERIC code ED368315.

Fryer, C. \& Wong, L. (1998). Sexual harassment: Experiences of Japanese women studying in Canada. TESL Canada Journal 15(2). 75-78.

Guerrero, E., Jr. (2006). The road less traveled: Latino students and the impact of studying abroad (Doctoral dissertation; University of California, Los Angeles). Retrieved from Dissertation Abstracts International. (AAT 3249418)

Hadis, B. F. (2005). Why are they better students when they come back?: Determinants of academic focusing gains in the study abroad experience. Frontiers: The Interdisciplinary Journal of Study Abroad, $11,57-70$.

Harden, R. (2007). Identities in motion: An autoethnography of an African American woman's journey to Burkina Faso, Benin, and Ghana (Doctoral dissertation; Bowling Green State University). Retrieved from Dissertation Abstracts International. (AAT 3262332)

Hembroff, L. A., \& Rusz, D. L. (1993). . Minorities and overseas studies programs: Correlates of differential participation. New York, New York: Council on International Educational Exchange. (Eric document reproduction service no. ED368283)

hooks, b. (1994). Teaching to transgress: Education as the practice of freedom. New York, NY: Routledge.

Hunter, B., White, G. P., \& Godbey, G. C. (2006). What does it mean to be globally competent? Journal of Studies in International Education, 10(3), 267-285 
Hurtado, S., Milem, J., Clayton-Pedersen, \& Allen, W. (1999). Enacting diverse learning environments: Improving the climate for racial/ethnic diversity in higher education, 26(8). Washington, DC: George Washington University, Graduate School of Education and Human Development: ASHE-ERIC Report.

Ingraham, E. C., \& Peterson, D. L. (2004). Assessing the impact of study abroad in student learning at Michigan State University. Frontiers: The Interdisciplinary Journal of Study Abroad, 10, 83-100. Retrieved from http://www.frontiersjournal.com/issues/vol10/vol1005_IngrahamPeterson.pdf

Institute of International Education (2008). Study Abroad White Paper Series: Meeting America's Global Education Challenge. Expanding education abroad at U.S. Community colleges. Retrieved from file://localhost/from http/::www.iie.org:Research-and-Publications:Publications-andReports:IIE-Bookstore:Expanding-Education-Abroad-at-US-Community-Colleges

Jackson, M. J. (2006). Traveling shoes: Study abroad experiences of African American students participating in California State University international programs (Doctoral dissertation, University of San Francisco). ProQuest Dissertations and Theses. Retrieved from http:/ / search.proquest.com/docview/304909330? accountid=10351

Jayakumar, U. M. (2008, Winter). Can higher education meet the needs of an increasingly diverse and global society? Campus diversity and cross cultural workforce competencies. Harvard Educational Review, 78(4), 615-651.

Kasravi, J. (2009). Factors influencing the decision to study abroad for students of color: Moving beyond the barriers (Doctoral dissertation; University of Minnesota). Retrieved from Dissertation Abstracts International. (AAT 3371866)

Kuh, G. (2011). Inspiring success on a dime: growing and enhancing high impact practices and high quality opportunities while maximizing resources. [Powerpoint presentation]. NAFSA Region VI Drive Conference April 13, 2011, University of Riverside, California.

Landau, J., \& Moore, D. C. (2001). Towards reconciliation in the motherland: Race, class, nationality, gender, and the complexities of American student presence at the University of Legon. Frontiers: The Interdisciplinary Journal of Study Abroad, 7, 25-59.

Lincoln, Y. S., \& Guba, E. G. (1985). Naturalistic Inquiry. Beverly Hills, CA: Sage.

Lindsey, E. W. (2005). Study abroad and values development in social work students. Journal of Social Work Education, 43(2),229-249.

Locklin, R. B. (2010). Weakness, belonging, and the Intercordia experience: The logic and limits of dissonance as a transformative learning tool. Teaching Theology and Religion, 13(1), 3-14.

Locks, A., Hurtado, S., \& Bowman, N. A. (2008). Extending notions of campus climate and diversity to students transition to college. The Review of Higher Education, 31(3), 257-285.

Malmgren, J., \& Galvin, J. (2008). Effects of study abroad participation on student graduation rates: A study of three incoming freshmen cohorts at the University of Minnesota, Twin Cities. National Association of Academic Advising Association Journal, 28(1), 29-42.

Milem, J. F., Chang, M. J., \& Antonio, A. L. (2005). Making diversity work on campus: A research-based perspective. Washington, DC: American Association of Colleges and Universities.

Morgan, R., M., Mwegelo, D. T., \& Turner, L. N. (2002). Black women in the African diaspora seeking their cultural heritage through studying abroad. NASPA Journal, 39(4), 333-353.

Neff, L., R. (2001). Discovering heritage and more by studying abroad. Black Issues in Higher Education, 18(12), 38-39.

$\mathrm{Ng}, \mathrm{H}$. (2004). Sojourners' truth: Intergenerational conflict and racial identity attitudes among second-generation Asian American participants in college study abroad programs in Asia (Doctoral dissertation; The Wright Institute). Retrieved from Dissertation Abstracts International. (AAT 2004-99013-052) 
Niser, J. C. (2010). Study abroad education in New England higher education: A pilot survey. International Journal of Educational Management, 24(1), 48-55.

Paige, R. M., Fry, G. W., Stallman, E. M., Josic, J., \& Jon, J. (2009). Study abroad for global engagement: The long-term impact of mobility experiences. Intercultural Education, 20, S29-S44.

Penn, E. B., \& Tanner, J. (2009). Black students and international education: An assessment. Journal of Black Studies, 40(2), 266-282.

Pierce, C. (1974). Psychiatric problems of the Black minority. In S. Arieti (Ed.), American handbook of psychiatry (pp. 512-523). New York, NY: Basic Books.

Pierce, C. (1995). Stress analogs of racism and sexism: Terrorism, torture, and disaster. In C. Willie, P. Rieker, B. Kramer, \& B. Brown (Eds.), Mental health, racism and sexism (pp. 277-293). Pittsburgh, PA: University of Pittsburgh Press.

Raby, R. L. (1998). Looking to the future: Report on California Community College international and global education program. A report on activities funded by the Chancellor's Office for the California Community Colleges 1997-1999 Fund for Instructional Improvement Research Grant. Sacramento, CA: Chancellor's Office.

Raby, R. L., \& Valeau, E. J. (2007). Community college international education: Looking back to forecast the future. New Directions for Community Colleges, 2007(138), 5-14. doi:10.1002/cc.276

Ramirez-Clemens, C. (2002). A descriptive study of demographic characteristics and perceptions of cross-cultural effectiveness of diverse students at Obio University in relation to study abroad (Doctoral dissertation; Ohio University). Retrieved from Dissertation Abstracts International. (AAT 3062149)

Rawlins, R. (2012). "Whether I'm an American or not, I'm not here so you can hit on me": Public harassment in the experience of U.S. women studying abroad. Women's Studies, 41, 476-497.

Raymondi, M. D. (2005). Latino students explore racial and ethnic identity in a global context (Doctoral dissertation; State University of New York at Binghamtom). Retrieved from Dissertation Abstracts International. (AAT 3153765)

Rossman, G. B., \& Rallis, S. F. (2003). Learning in the field: An introduction to qualitative research (2nd ed.). Thousand Oaks, CA: Sage.

Saldaña, J. (2009). The coding manual for qualitative researchers. Los Angeles, CA: Sage.

Scoffham, S., \& Barnes, J. (2009). Transformational experiences and deep learning: The impact of an intercultural study visit to India on UK initial teacher education students. Journal of Education for Teaching: International Research and Pedagogy, 35(3), 257-270.

Shulock, N., Moore, C., Offenstein, J., Kirlin, M. (2008). It Could Happen: Unleashing the Potential of California's Community Colleges to Help Students Succeed and California Thrive. Retrieved from California State University, Sacramento, Institute for Higher Education Leadership and Policy website: http://www.csus.edu/ihelp/PDFs/R_ItCouldHappen_02-08.pdf

Solórzano, D. (1998). Critical race theory, racial and gender microaggressions, and the experiences of Chicana and Chicano scholars. International Journal of Qualitative Studies in Education, 11(1), 121-136.

Solórzano, D., Ceja, M., \& Yosso, T. (2000). Critical race theory, racial microaggressions, and campus racial climate: The experiences of African American college students. Journal of Negro Education, 69(1/2), 60-73.

Smith, W. A., Hung, M., \& Franklin, J. D., (2011). Racial battle fatigue and the "mis"education of black men: Racial microaggressions, societal problems, and environmental stress. The Journal of Negro Education, 80(1), 63-82.

Stallman, E. M. (2009). Intercultural competence and racial awareness in study abroad (Doctoral dissertation; University of Minnesota). Retrieved from UMI Microform 3371916. Ann Arbor, MI: ProQuest LLC. 
Sue, D.W., Capodilupo, C.M, Torino, G.C., Bucerri, J.M., Holder, A.M.B, Nadal, K.L., Esquilin, M. (2007). Racial microaggressions in everyday life: Implications for clinical practice. American Psychologist. 62(4) 271-286.

Talburt, S., \& Stewart, M. A. (1999). What's the subject of study abroad?: Race, gender, and 'living culture.' Modern Language Journal, 83(2), 163-175. doi:10.1111/ 0026-7902.00013

Tesoriero, F. (2006). Personal growth towards intercultural competence through an international field education programme. Australian Social Work, 59(2), 126-140.

Twombly, S.B. (1995). Piropos and friendships: Gender and culture clash in study abroad. Frontiers: The Interdisciplinary Journal of Study Abroad, 1, 1-27.

Wick, D. J. (2011). Study abroad for students of color: A third space for negotiating agency and identity. (Unpublished doctoral dissertation; San Francisco State University), received from author on June 26, 2011).

Williams, T. R. (2005). Exploring the impact of study abroad on students' intercultural communication skills: Adaptability and sensitivity. Journal of Studies in International Education, 9(4), 356-371. doi:10.1177/1028315305277681

Willis, T. (2012). Rare but there: An intersectional exploration of the experiences and outcomes of Black women who studied abroad through community college

programs. (Doctoral dissertation; California State University, Long Beach). Retrieved from ProQuest Dissertations and Theses. (Accession Order No. [3533746]) 